\title{
The Environmental Load Reducing as a Factor of Improving the Quality of Life of the Coal Mining Region Population
}

\author{
Ekaterina Slesarenko ${ }^{1}$, Oksana Sheveleva ${ }^{1, *}$, Natalia Kudrevatykh ${ }^{1}$, and Nina Vagina ${ }^{1}$ \\ ${ }^{1}$ T.F. Gorbachev Kuzbass State Technical University, Department of Finance and Credit, 650000 \\ Kemerovo, 28 Vesennya st., Russian Federation
}

\begin{abstract}
The need to reduce the environmental load as the most important factor of improving the quality of life of the population and preventing the outflow of human resources from the coal mining region is substantiated in the article. The study allowed identifying a number of socio-economic threats associated with the influence of high environmental load in coal mining regions, namely: the presence of adverse sanitary and hygienic factors affecting the state of health and the quality of life of people; the excess of the average Russian share of jobs with unsatisfactory conditions for ensuring their compliance with sanitary and epidemiological standards and regulations in coal mining regions; increase in the incidence rate. The entire list of identified threats has the most direct impact on the indicators of population growth and migratory movement leading to a lack of human resources in a region. First of all, it is proposed to reduce the environmental load of a mining region through the implementation of a concept aimed at improving the environmental safety of the industry at all stages: from exploratory activities to mine abandonment. And secondly, the environmental load should be reduced on the basis of a set of measures affecting such important areas of regional economic development as diversification of industrial production (increasing the share of industries with lower environmental load on the ecosystem), developing a high-tech business and mainstreaming responsible consumption ideas in the public mind and businesses.
\end{abstract}

\section{Introduction}

In the Russian Federation, nine main strategic development goals until 2024 are set, which should not only ensure the socio-economic, scientific and technical development of the country, but also be aimed at increasing the number of citizens, raising their standard of living, creating comfortable conditions for self-fulfillment. Environment is included in the list of these goals, and this fact allows suggesting that the solution of environmental problems is one of the most important priorities of the country, and, first of all, of the commodity-dependent regions, where this problem is especially relevant.

\footnotetext{
*Corresponding author: shob.fk@kuzstu.ru
} 
The emphasis on the development of the extractive industry without due attention to environmental issues contributes to air and water pollution, deterioration of soil and vegetation cover qualities, and destruction of forests. In this regard, the need to reduce the environmental load by increasing the environmental safety of the coal industry, diversifying regional industrial production and creating high-performance jobs is identified by researchers as the most important factor in improving the quality of life of the population and preventing the outflow of human resources [1-4].

In this study, an assessment of the impact of environmental factors on the quality and standard of living of the population is presented on the example of the Kemerovo region, as a representative of coal mining regions with a high share of employees in this sector. So, in 2017, 116.2 thousand people worked in the coal mining industry of Kuzbass $(9.7 \%$ of those employed in the region's economy), in 2018 this number increased to 119.2 thousand people ( $10 \%$ of those employed in the economy).

\section{Materials and Methods}

The study made it possible to reveal a number of problems associated with the influence of high environmental load on the living standards of the Kemerovo region population.

This is, firstly, a significant level of influence of sanitary and hygienic factors on the health status of the population consisting in chemical pollution of water, air, soil, as well as the harmful effects of physical factors.

The environmental factors indicated in the Federal Law "On the Sanitary and Epidemiological Welfare of the Population", that contribute to negatively affect the state of human health, are usually divided in three groups to be analyzed:

- socio-economic factors;

- sanitary and hygienic factors;

- lifestyle factors.

When the constituent entities of Russia were ranked by federal bodies supervising the protection of consumer rights and human well-being according to the simultaneous influence of various factors on the state of health, the Kemerovo Region in 2018 entered the first cluster, which is characterized by a strong level of influence of factors of a sanitary and hygienic and lifestyle factors and an average influence of socio-economic factors.

The integral indicator of the sanitary and hygienic situation in Kuzbass made it possible to include it in the number of regions with a higher than average rank, which indicates a significant influence of factors related to chemical pollution of water, soil, air, as well as the impact of physical factors (vibration, electric and magnetic fields, radiation) on the state of health of citizens. Sanitary and hygienic factors of the complex chemical load affect the incidence of the population, the prevalence of respiratory diseases, endocrine system, the presence of congenital anomalies in children, mortality rates, including mortality caused by malignant neoplasms and diseases of the circulatory system.

\section{Results and Discussion}

In 2018, Kuzbass was assigned the maximum rank (among several other regions) when distributing the constituent entities of Russia according to the level of influence of working conditions on the health status of the working population. The factors of this group were: the temporary disability incidence rate; the prevalence of digestive system and respiration diseases; injury rate; the general mortality rate, including from diseases of the circulatory system, malignant neoplasms. 
Kuzbass is traditionally one of the most polluted subjects of the Siberian Federal District. About 50 coal, metallurgical and chemical industry enterprises operate in the region, which are environmentally unfavorable activities that have a diverse negative impact on the environment. In this regard, many cities of Kuzbass (Novokuznetsk, Prokopievsk and others) often appear in various reports as territories with a high level of the environmental load.

At the beginning of 2019, the Ministry for Natural Resources and Environment of the Russian Federation published a report on air pollution in the regions, compiled on the basis of the air samples in 2017 , where pollutants exceeded the maximum permissible concentration. Kemerovo region was in eighth position.

An assessment of the air state by the federal bodies supervising the protection of consumer rights and human welfare also indicates that Kuzbass is traditionally one of the ten regions with a maximum proportion of air samples in urban areas, in which the maximum permissible concentration of harmful substances is exceeded. In 2018, Kuzbass ranked sixth among the leading regions in this field. Moreover, over the course of five years, a steady dynamics has been observed in the increase in the proportion of air samples exceeding the permissible concentration (over five years the growth was 2.6 times). The frequency of registration of air samples with such an excess in 2014 in Kuzbass was $0.83 \%$, increasing to $2.17 \%$ by 2018 . Outstripping growth rates are recorded only in the Irkutsk region.

The composition of air polluting substances, in which the highest maximum single fractions of samples in Kuzbass in 2018 were noted, included:

- mercury $-1.69 \%$ of samples in excess of the permissible concentration (second place in the country, after the Yaroslavl region);

- hydrogen fluoride $-13.3 \%$ of samples (second place in the country, after the Irkutsk region);

- fluorine and its compounds - $13.3 \%$ of samples (second place in the country, after the Irkutsk region);

- benzapyrene $-30 \%$ of samples (second place in the country, after the Republic of Buryatia).

In 2019, the Kemerovo Center for Hydrometeorology and Environmental Monitoring in the city of Prokopyevsk noted an increased level of air pollution by suspended solids; high levels of pollution in Kemerovo and very high in Novokuznetsk in terms of benzopyrene content. In 2019, in the capital of Kuzbass, the average annual benzapirene content exceeded the permissible concentration by 2.7 times, having increased by $28.6 \%$ over four years (the maximum average monthly concentration was $14.6 \mathrm{MPC}$ ). In Novokuznetsk, in 2019, the average annual concentration of benzopyrene was 5.8 MAC (maximum monthly average concentration - 37.6 MAC).

Benzapyrene is an organic compound with a strong carcinogenic effect, which is formed during the combustion of hydrocarbon fuels. The extremely harmful effect of benzapirene on the human body is considered in the works of both Russian and foreign scientists [5-7], this problem was also raised in our work [8]. The negative effect of harmful mercury vapor also raises no doubts [9-10].

In addition, in 2018, Kuzbass was in first place in the country in the content of average daily maximum permissible concentrations of harmful substances in gaseous fluoride compounds (in terms of fluorine): the proportion of samples exceeding the maximum permissible concentration was $5.31 \%$.

The low air quality level was influenced by often adverse weather conditions, the use of obsolete equipment (including environmental) at industrial enterprises, the active use of coal as mineral fuel by boiler houses and the public. 
According to the Procedure for the work that regulates the level of pollutants in the air during adverse weather conditions, approved in 2012 in the Kemerovo Region, measures for reducing emissions at 72 industrial sites at economic facilities of the cities of Kemerovo, Novokuznetsk, and Prokopyevsk were agreed for 2019.

The main river of the Kemerovo region - Tom - and its tributaries are polluted by sewage from mining, metallurgical, energy and chemical industries. In 2019, compared with 2018, either the deterioration in water quality or the invariance of the previously assigned pollution level was observed in different sections of the Tom River.

In addition, many natural water inflows have been disrupted in Kuzbass, including by abandoned mines and opencasts. The high level of pollution of surface and ground water in the region contributes to the creation of a tense situation in providing the population with drinking water of appropriate quality.

The distribution of Russian regions by the share of soil samples from the residential zone reflecting the excess of sanitary and chemical indicators of hygienic standards led to the fact that in 2018 Kuzbass fell into the group of regions with an excess of the average Russian indicator - from 1.1 to 1.4 times . The level of soil pollution was influenced by both industrial toxicants, as well as soil contamination with industrial waste, dumping, discharge of contaminated industrial wastewater.

In addition, after coal mining there are areas of land that are not suitable for further use; voids in the soil appear, which can be dangerous not only to the ecosystem, but lead to the subsidence of roads and foundations.

In order to reduce the environmental load on the soil cover and to combat the uncontrolled waste disposal in Kuzbass, in 2009 the Kuzbass Association of Waste Processors was established, which is a regular participant in public environmental events, initiates projects for the separate collection of waste, and works among the population to promote an environmental culture.

As noted above, a significant contribution to achieving high rates of morbidity and mortality in the Kemerovo region is made by indicators capturing the impact of a set of physical and chemical factors on the environment.

According to the World Health Organization, the environment, which is constantly and in a complex way affected by pollution of water, soil and air, increases the incidence of the population by $15-25 \%$. This fact is confirmed by a number of studies [11-15].

In this regard, Kuzbass is:

- in the middle zone among Russian regions in terms of mortality in 2018 with the number of 14-15 deaths per 1000 people (the average rate in the Russian Federation is 12.4 people);

- in the middle zone according to cases of diseases per 100 thousand people with the incidence rate of 155-167 thousand cases;

- in the zone of regions exceeding the average Russian rate of mortality from malignant neoplasms by 1.1-1.4 times in 2017;

- in the zone of regions exceeding the national average rate of children and adults with asthma by 1.1-1.4 times in 2017 .

Exceeding benzapyrene, hydrogen fluoride, saturated hydrocarbons, hydrogen chloride and other chemicals in the air can provoke the diseases of the respiratory, immune, nervous, genitourinary, musculoskeletal, and reproductive, circulatory systems, and also have a negative impact on the development of human body. In 2018, the Kemerovo region was included in the number of 11 regions, where a significant rate of mortality from malignant neoplasms compared with the all-Russian indicators was closely related to the effect of carcinogens on the air.

Secondly, there are a significant number of jobs with unsatisfactory conditions for ensuring their compliance with sanitary and epidemiological standards and regulations. 
One of the fundamental directions of state and regional labor policy is the preservation of the health of the working population, as ensuring safe working conditions and timely and high-quality prevention of occupational diseases reduce injuries and professional pathologies, thereby saving valuable labor resources and lowering the rate of temporary disability and related financial and economic losses.

In 2018, in the Kemerovo region, the share of enterprises of the first group of sanitary and epidemiological welfare (jobs which are more in line with sanitary and epidemiological standards and regulations) amounted to only $7.18 \%$, which is almost below the all-Russian indicator (27.48\%) in almost 4 times. The share of enterprises of the third group (with extremely unsatisfactory working conditions), in contrast, was much higher in Kuzbass $(30.26 \%)$ than the national average (7.13\%).

Extractive industry enterprises were among the objects with the most unfavorable working conditions, representing an extremely high risk of occupational disability. In the structure of the professional pathology of coal mining enterprises, the maximum share falls on diseases caused by exposure to physical factors and associated with physical overload and overstrain of individual organs and systems.

In 2018, in the Russian Federation as a whole, the largest share of newly diagnosed pathologies in the structure of occupational morbidity by various types of economic activity was recorded among employees of mining enterprises $-47.59 \%$ of the total number of cases.

The rate of occupational morbidity by extractive industries in Russia in 2018 amounted to 25 cases per 10 thousand employees, which is 11.6 times more than in manufacturing industries and 21 times more than the average of all types of economic activity in the country. The positive dynamics is that over the past five years there has been a decrease in the occupational morbidity rate by $22.8 \%$ in type of economic activity "Mining operations".

In the Kemerovo region (9.96 cases per 10 thousand employees), the excess of the average Russian indicators of occupational diseases (1.17 cases per 10 thousand employees) was 8.5 times. Over the past five years, there has been a decrease in cases of occupational diseases by $23.4 \%$, but in 2018 Kuzbass was in third place among the regions leading in occupational diseases of the working population (after the Republic of Khakassia and the Republic of Sakha). The number of workers employed in jobs with dangerous or harmful working conditions decreased by 12.6 thousand people or $5.8 \%$, amounting to 204.8 thousand people in 2018 or $67.1 \%$ of the total number of employees.

The complexity of work and work in dangerous and harmful production conditions contributes to the fact that in 2015-2018 the average level of wages in the extractive industries of Kuzbass was the highest of all types of economic activity (57868 rubles, an increase over 4 years was $31.9 \%$ ), and at coal mining enterprises - 58,924 rubles (an increase by $32.3 \%$ ). As a percentage of the average in the region, wages at extractive industry enterprises amounted to $155.2 \%$, and in coal mining $-155.0 \%$.

Thirdly, there is a steady increase in the natural population decline due to a decrease in the birth rate with a simultaneous increase in mortality rates.

The indicators of population growth in Kuzbass are disappointing. Thus, the birth rate (24158 people) in 2019 was $36.5 \%$ lower than the death rate (38028 people), and in 2018 2019 there is a negative effect on the population: the number of deaths is growing (by $1.5 \%$ or 573 people), and the number of births is reducing (by $8.8 \%$ or by 2317 people). As a result, the rate of natural population decline is increasing by $14 \%$ or 1744 people (up to 13870 people in 2019 compared with 12126 people in 2018).

In terms of a thousand people, the natural decline in 2019 amounted to 5.2 people, increasing by 0.6 people against the rate of 2018 . Among the causes of death, mortality rates due to circulatory system diseases $(45.7 \%$ of the deceased), neoplasms $(17 \%)$, and 
respiratory diseases (4.4\%) prevail. Moreover, the dynamics shows an increase in mortality due to all types of morbidity listed above, and the increase in mortality due to diseases of the circulatory system was $17.1 \%$.

Fourth, the dynamics of the negative balance of the migration flow is traced.

An unfavorable environmental situation is one of the reasons for the negative balance of the migration flow of the population. In 2019, the number of arrivals to the region amounted to 70,729 people; the number of departures being 73238 people (migration decrease was 2509 people or 9.4 people per 10 thousand people). In 2018, the migration decline was 8413 people, or 31.3 people per 10 thousand people. The increase in migration outflow was due to both the desire of people to move to more environmentally friendly areas and the closure of a number of mining enterprises, which meant the loss of the usual jobs by employees.

Due to the unfavorable environmental situation in a number of Russian regions, the country launched the implementation of the Federal Clean Air project, which aims to significantly reduce its pollution, especially in large industrial centers, as well as to create an effective air quality monitoring and control system. In the implementation of this project, the city of Kemerovo region - Novokuznetsk - was among the priority cities.

\section{Conclusion}

In 2019, the region itself announced the implementation of the concept of "Clean Coal Green Kuzbass", indicating a priority in ensuring environmental safety, which should contribute to the achievement of the following positive aspects in the development of the coal industry:

- reduction of environmental damage;

- introduction of technologies to save human life and health;

- increase in performance due to the intensification of activities;

- use of advanced world technologies in the field of coal mining, processing and transportation;

- comparison of financial and economic benefits from the activities of coal mining enterprises with the environmental damage caused to the ecosystem by their activities, and the refusal to further exploit a number of enterprises in the event of multiple excesses of social and environmental damage over possible financial and economic benefits.

In addition, an important innovation in the work to improve the environment in Kuzbass is the introduction of a socio-environmental impact assessment, which allows, before starting license tendering processes and issuing extraction licenses to enterprises, conducting both their environmental and social impact assessments in order to maximize the interests of the population. At the same time, the conditions for ensuring industrial safety, conservation of mineral resources and environmental protection are prescribed in the license.

And finally, it was in Kuzbass for the first time in Russia that began to develop a regional environmental standard with the aim of ranking enterprises depending on the performance of applied environmental technologies. Environmental passports of enterprises of the first hazard category were formed, which included data on the boundaries of sanitary protection zones, technological standards and roadmaps to improve the environmental performance of coal mining and processing.

At the same time, in order to ensure a decent quality of working and living conditions of the Kemerovo region population and as an important condition for preventing the outflow of labor resources from the region, along with improving the environmental safety of coal mining, it is necessary to develop system measures that go far beyond the boundaries of the (mining) industry alone, namely: 
- creation of high-performance jobs in manufacturing industries [16];

- creation of conditions for the implementation of entrepreneurial and investment initiatives, especially in the field of high-tech business;

- mainstreaming responsible consumption ideas in the public mind and businesses.

\section{References}

1. S. S. Oganesyan, 7th icCSBs 2018 - The Ann. Int. Conf. on Cogn. - Soc., and Beh. Sci., 1, 2357-1330 (2019)

2. D.K-S. Bataev, V.Kh. Khadisov, A.Z. Abukhanov, M.Sh. Salamanova, IOP Con. Ser.: Mat. Sci. and Eng., 663, 012047 (2019)

3. S. Asumadu-Sarkodie, V. Strezov, Y.Jiang, T. Evans, Sci. of The Tot. Env., 683, 1 (2019)

4. D. Spirkova, J.Kloudova, A. Kljucnikov, B. Stehlikova, J. of Comp., 11(1), 116 (2019)

5. T. Yu. Gavrilenko, O. V. Grigorenko, I.P. Provorova Advances in Economics, Business and Management Research, 119, 79 (2019).

6. K. Mustafina, J. of Tour., Cult. And Ter. Devel., 5, 109 (2012)

7. S. E. Stetsenko, N. A. Yastrebova, I. N. Eterevskaya, IOP Con. Ser.: Mat. Sci. and Eng., 753, 032023 (2020)

8. E. V. Slesarenko, E. A. Radionova, O. B. Sheveleva, N. V. Kudrevatykh, T. F. Mamzina, IOP Conf. Series: Earth and Env. Sci., 224, 012043 (2019)

9. R. Pamphlett, S. Kum Jew, S. Cherepanoff, PLoS ONE, 14(8) (2019)

10. S. G. Oz, M. Tozlu, S. Siddika Yalcin, T. Sozen, and G. Sain, Guven Inhalation Toxicology, 24(10), 652 (2012)

11. F. Mariani, A. Pérez-Barahona, Natacha Raffin, RePEc, 48, 3 (2008)

12. F. Ramírez, A. J. Grau, Sustainability, 9, 1093 (2017)

13. Y. Wu, K. Hu, Y. Han, Q. Sheng and Y. Fang, Int. J. Environ. Res. Public Health, 17, $906(2020)$

14. V. Kontis, J. E. Bennett, C. D. Mathers, G. Li, K. Foreman, M. Ezzati, The Lancet, 389, 10076 (2017)

15. A. J. Idrovo, Cadernos de saúde pública, 27(6), 1175-84 (2011)

16. O. B. Sheveleva, E. V. Slesarenko, V. V. Mishchenko and A. B. Kiselev, IOP Conf. Series: Earth and Environmental Science, 315, 052060 (2019) 